\title{
A novel TiO2-TiC-TiC0.3N0.7-C-SiCN multiphase ceramic nanocomposite from preceramic polymer pyrolysis
}

\section{Rahul Anand}

Bibhuti B Nayak

Shantanu K Behera ( $\sim$ behera@alum.lehigh.edu )

National Institute of Technology Rourkela https://orcid.org/0000-0001-5986-5605

\section{Research Article}

Keywords: Polymer derived ceramics, Silicon carbonitride, TiO2, TiC, Nanocomposite

Posted Date: February 23rd, 2022

DOI: https://doi.org/10.21203/rs.3.rs-1333715/v1

License: (c) (i) This work is licensed under a Creative Commons Attribution 4.0 International License. Read Full License 


\section{Abstract}

The current investigation describes the synthesis of SiTiCNO ceramics derived from a mixture of a preceramic polymer (polyvinylsilazane) and tetrabutyl orthotitanate precursors by crosslinking at $300^{\circ} \mathrm{C}$ and pyrolysis in the temperature range of $900{ }^{\circ} \mathrm{C}-1400{ }^{\circ} \mathrm{C}$ in flowing nitrogen atmosphere. Crosslinked precursor was studied through DSC-TG to estimate ceramization temperature as well as ceramic yield. Further, the evolution of phase and nanostructure with temperature in the composite SiTiCNO ceramics was analyzed by the help of different characterization techniques, such as XRD, Raman, and electron microscopy. Ti-doped SiCN ceramic systems appeared as single-phase SiTiCNO amorphous ceramics up to $1100{ }^{\circ} \mathrm{C}$. The phase separation of SiTiCNO ceramics started at $1200{ }^{\circ} \mathrm{C}$ and exhibited $\mathrm{TiO}_{2}$ nanocrystals in the SiCN matrix. Ti-doping was found to accelerate the separation of the free carbon phase from the SICN matrix, and the said carbon had better graphitic order in the Ti-doped samples as compared to the undoped $\mathrm{SiCN}$ of equivalent thermal history. At $1400^{\circ} \mathrm{C}$, high temperature stable phases such as $\mathrm{TiC}$ and $\mathrm{TiC}_{0.3} \mathrm{~N}_{0.7}$ were formed along with predominant rutile- $\mathrm{TiO}_{2}$ phase within the Si-Ti-O-C-N matrix. A uniform distribution of these nanocrystals in the $\mathrm{SiCN}$ matrix at $1400{ }^{\circ} \mathrm{C}$ were observed through TEM/HRTEM analysis. The current work exhibits the formation of a unique multiphase composite with the co-existence of nanocrystalline phases uniformly distributed within a polymer derived ceramic matrix.

\section{Introduction}

Silicon-based polymer derived ceramic (PDC) nanocomposites have recently gained a lot of attention due to their low processing temperature, excellent thermal stability and thermomechanical properties, and excellent resistance towards oxidation and corrosion.[1-7] Previous investigations have evidenced that the nanocomposites of PDC derived SiCN ceramics and a filler such as glass[6, 8], $\mathrm{ZrO}_{2}$ [8], YSZ[9], $\mathrm{SiC}[10], \mathrm{BN}[11]$, or $\mathrm{TiB}_{2}$ [12] exhibit improved high temperature properties than the pure SiCN ceramics. These fillers can make considerable improvements in the different properties (thermal, mechanical, electrical, optical, etc.) of $\mathrm{SiCN}$ with improved homogeneity of the distribution of the components within the amorphous matrix at the nanoscale [13-16], since the properties of the nanocomposites mostly depend on their phase assemblage and microstructure. $[3,17,18]$ Therefore, initial precursors and high temperature processing conditions can have a profound influence on the final properties of polymerderived ceramic (PDC) nanocomposites.[19, 20] Synthesis of such nanocomposites has been performed through the pyrolytic conversion of single source polymeric precursors. For instance, different metal precursors of $\mathrm{Al}[21,22], \mathrm{Y}[23], \mathrm{Ti}[24,25], \mathrm{Zr}[26-28]$, and $\mathrm{Hf}[29]$ were used to transform the molecular structure of the preceramic precursors that exhibited altered microstructures of SiCN ceramics upon pyrolysis. These metals nucleate and crystallize in-situ as metal oxides/nitrides/carbides or silicates within the SiCN matrix during the thermal treatment at temperatures above $1000{ }^{\circ} \mathrm{C}$ and form uniform nanostructured composites.[30] PDC modified with the transition metal elements ( $\mathrm{Zr}, \mathrm{Hf}, \mathrm{Ta}$, and $\mathrm{Ti}$ ) show few $\mathrm{C}_{\text {free }}$ with completely different molecular structure.[31, 32] For instance, $\mathrm{Zr}$ doping to SiCN lead to the precipitation of $\mathrm{t}-\mathrm{ZrO}_{2}$ phases, which reinforces the nanocomposites and hence enhances thermal 
stability towards crystallization, oxidation and corrosion even at temperatures above $1300^{\circ} \mathrm{C} .[27,28,33]$ B-doping into $\mathrm{SiCN}$ ceramic resulted in the high temperature stability towards crystallization up to temperature as high as $2200^{\circ} \mathrm{C}$.[14, 34] Further, incorporation of B into SiZrCN ceramics diminishes the crystallization of $\mathrm{ZrC}_{\mathrm{x}} \mathrm{N}_{\mathrm{y}}$ and suppress the reaction of $\mathrm{SiN}_{\mathrm{x}}$ with $\mathrm{C}$, resulting in an improved thermal stability of SiZrBCN as compared to SiZrCN ceramics.[35] Hf-doping to the SiCN matrix improved the thermal stability as well as oxidation and corrosion resistance. $[5,13,36]$ A new class of $\mathrm{SiC} / \mathrm{Hf}_{\mathrm{y}} \mathrm{Ta}_{1-\mathrm{y}} \mathrm{C}_{\mathrm{x}} \mathrm{N}_{1-\mathrm{x}} / \mathrm{C}$ nanocomposite with improved oxidation resistance was synthesized at $1900{ }^{\circ} \mathrm{C}$, and the composition as well as thickness of the $\mathrm{HfC}_{x} \mathrm{~N}_{1-x}$ and $\mathrm{TaC}_{x} \mathrm{~N}_{1-x}$ core shell structures can be tuned with varying the $\mathrm{Hf}: \mathrm{Ta}$ atomic ratio.[31] Furthermore, the Ti-doping through Ti-isopropoxide precursor within the silazane precursor resulted into anatase precipitation within the Si-C-N matrix at $1000^{\circ} \mathrm{C}$, which eventually showed phase transformation into rutile above $1200^{\circ} \mathrm{C}$.[37] Present work is aimed towards development of such a Si/Ti-based nanocomposite ceramics by altering the polyvinylsilazane precursor with a molecular precursor of Ti through PDC route. The transformation of the precursor polymer to ceramic was studied through thermogravimetry (TG) and differential scanning calorimetry (DSC). The phase and nanostructural features of the pyrolyzed SiTiCNO ceramics were investigated through the Raman spectroscopy, X-ray diffraction (XRD), high resolution transmission electron microscopy (HRTEM). The formation of a unique multiphase nanostructured composite is exhibited from the pyrolysis of a Ti-doped polyvinylsilazane precursor polymer.

\section{Materials And Methods}

A commercially available polyvinylsilazane (Durazane ${ }^{\circledR 1800, ~ M e r k ~ C h e m i c a l s) ~ p r e c u r s o r ~ w a s ~ d o p e d ~ b y ~}$ Ti using tetrabutyl orthotitanate $\left(\mathrm{Ti}_{(}\left(\mathrm{OC}_{4} \mathrm{H}_{9}\right)_{4}\right.$, Alfa Aesar, USA) as a metal precursor. The molecular structure of polyvinylsilazane used comprises $20 \%$ methyl/vinyl and $80 \%$ of methyl/hydride silazane based monomers (Fig. 1). Tetrabutyl orthotitanate was dissolved in ethanol and instantly mixed with the PVS solution in a ratio of Ti : Si as 0.2 by mol\%. Also, $1 \mathrm{wt} \%$ of dicumyl peroxide (DCP, Sigma-Aldrich ${ }^{\circledR}$, India) was added for easy crosslinking of mixed solution. The crosslinking reaction was carried out at $300^{\circ} \mathrm{C}$ for 2 hours in a controlled box furnace having a vertical glass column attached with the flowing $\mathrm{N}_{2}$ source. The key crosslinking reaction involves combination of $\mathrm{Ti}$ with $\mathrm{Si}$ via $\mathrm{O}$ bond, hydrosilylation between vinyl and Si-H groups and polymerization of the vinyl groups.[37, 38] The crosslinking process resulted a thermoset (pale yellow solid mass), which was milled in fines (Fig. 2a) using a High-energy mechanical milling (SPEX 8000M SamplePrep, USA) by means of zirconia pot and ball.

The resultant powder (termed PVS-Ti(b)-300) was heat treated in a tube furnace at high temperatures ranging $900^{\circ} \mathrm{C}$ to $1400^{\circ} \mathrm{C}$, with a uniform heating rate of $2^{\circ} \mathrm{C} \mathrm{min}-1$ and nitrogen flow rate of $80 \mathrm{ml} \mathrm{min}^{-1}$. The resultant samples were dark colored powders, termed as PVS-Ti(b)-900 to PVS-Ti(b)-1400 for pyrolysis temperatures of $900^{\circ} \mathrm{C}$ (cf. Fig. 2(b)) and $1400^{\circ} \mathrm{C}$ (cf. Fig. 2(c)).

Polymer to ceramic transformation and mass loss of crosslinked PVS-Ti(b)-300 sample during ceramization was determined by thermogravimetric (TG) analysis (Netzsch, Germany, STA/TG-DSC) 
under flowing nitrogen. The calorimetric aspects of the crosslinked sample during ceramic conversion reactions, phase formation and crystallization phenomena were also studied by differential scanning calorimeter (DSC) attached with TG analyzer. The dissolution of Ti into ceramic matrix of pyrolyzed $\mathrm{Ti}$ doped PVS sample were confirmed through energy dispersive spectroscope (EDS) data obtained through scanning electron microscopy (SEM, FEl, Technai ${ }^{\mathrm{TM}} \mathrm{G}^{2}$ Eindhoven, $\mathrm{NL}$ ) by applying $20 \mathrm{kV}$ accelerating voltage to the emission electron gun. Further, all the ceramic samples were scanned in the $1000 \mathrm{~cm}^{-1}$ to $2000 \mathrm{~cm}^{-1}$ spectral range through PL micro Raman spectrometer (XMB3000, WITec GmbH, Germany) having an Ar laser wavelength of $532 \mathrm{~nm}$. The acquired Raman spectra were analyzed to understand the structural evolution of the free carbon $\left(\mathrm{C}_{\text {free }}\right)$ phase within the ceramic matrix at different pyrolysis temperatures. Also, the pyrolyzed samples were evaluated by the X-ray diffractometer (Rigaku Ultima IV, Japan) using Cu-Ka radiation in the $2 \theta$ range of $10^{\circ}$ to $80^{\circ}$ at a scan rate of $20^{\circ} \mathrm{min}^{-1}$ to understand the phase evolution in the ceramic. The evolved nanostructure within the SiTiCNO ceramic matrix was observed by bright field and high resolution imaging using a transmission electron microscope (TEM, FEI Titan $\mathrm{G}^{2}$ 80-300) at an accelerating voltage of $200 \mathrm{kV}$. The sample for TEM observation were prepared by dropcasting a uniformly dispersed solution of the ceramic powders in isopropanol on a carbon coated copper grid (300 mesh, Ted Pella, USA). The HRTEM micrographs were analyzed by a Java-based image processor "ImageJ" to identify the nanostructured phases. The lattice fringes were obtained by applying fast Fourier-transform (FFT) algorithm on a selected area over the HRTEM micrograph and the fringe width were calculated from the inverse of the FFT (IFFT) image.

\section{Results And Discussion}

The thermal behavior of the crosslinked Ti-modified polyvinylsilazane precursor was studied up to 1500 ${ }^{\circ} \mathrm{C}$ and shown in TGA curve (Fig. 3). The PVS-Ti(b)-300 sample shows no loss up to $300{ }^{\circ} \mathrm{C}$ and a continuous mass loss of $20.65 \%$ up to $750{ }^{\circ} \mathrm{C}$. The cessation of mass loss after $750{ }^{\circ} \mathrm{C}$ indicated that the polymer to ceramic transformation is complete at this temperature, with the mass loss over the $300{ }^{\circ} \mathrm{C}$ $750{ }^{\circ} \mathrm{C}$ temperature range attributed to the evaporation of $\mathrm{H}_{2}$, carbon in the form of $\mathrm{CH}_{4}$, and other hydrocarbons $\left(\mathrm{C}_{n} \mathrm{H}_{m}\right)$ during the decomposition of the polymer precursor.[39]

A further small mass loss of $\sim 1 \%$ in the temperature range of $1100{ }^{\circ} \mathrm{C}-1500{ }^{\circ} \mathrm{C}$ was seen, which may be due to the loss of hydrogen or excess oxygen attached to, the Ti precursor. The total ceramic yield of the sample was found to be $78.2 \mathrm{wt} \%$, which is in good agreement with the theoretical yield $(71.1 \mathrm{wt} \%$, where yield of pure PVS was considered as $83 \mathrm{wt} \%$ ) of the selected composition for Ti-doped PVS in this work. The DSC thermogram of the sample (Fig. 3) shows a slow and constant rise of the curve up to $745^{\circ} \mathrm{C}$, which is due to the continuous transformation of the sample from polymeric to glassy state. Additionally, an exothermic peak at around $1328{ }^{\circ} \mathrm{C}$ as well as an endothermic peak at $1445^{\circ} \mathrm{C}$ appeared, which may be due to the development of new phases and their crystallization within the SiCN matrix.

Fig. 4a shows SEM micrograph illustrating the morphology of the ceramics obtained from pyrolysis of the crosslinked powders at $1400^{\circ} \mathrm{C}$ for 2 hours. Though the SEM micrographs do not show any 
nanostructural features within the ceramics, the superior thermal stability of the SiTiCNO ceramics can be observed with glassy morphological appearance even at $1400^{\circ} \mathrm{C}$. Further, the EDS map images shown in Fig. 4 (b-f) of the PVS-Ti(b)-1400 sample indicate the presence of $\mathrm{Si}, \mathrm{Ti}, \mathrm{C}, \mathrm{N}$, and $\mathrm{O}$ elements in the ceramic structure. The pyrolyzed SiTiCNO ceramics consists predominantly of $\mathrm{Si}, \mathrm{O}, \mathrm{C}, \mathrm{N}$, and the Ti distribution appears uniform throughout the ceramic microstructure.

The different phases evolved during different stages of pyrolysis were identified by analyzing XRD patterns of PVS-Ti samples of different thermal history (powders pyrolyzed in the temperature range of $900^{\circ} \mathrm{C}$ to $1400^{\circ} \mathrm{C}$, cf. Fig. 5).

The PVS-Ti(b)-900, PVS-Ti(b)-1000, and PVS-Ti(b)-1100 samples were found to be completely amorphous and monophasic. The broad hump ranging from $2 \mathbb{Z}=17^{\circ}$ to $28^{\circ}$ shows Si-O based bonds present in the SiCN structure. This occurs due to the substitution reaction between Si-H site of PVS precursor and Ti-O of tetrabutyl orthotitanate, which forms Si-O-Ti bond. Also, the hump may be of Si-O based bonds occurred due to oxygen adsorbed from the atmosphere due to the high affinity of silicon for oxygen.[40,41] Therefore, the hump remains present in all pyrolyzed samples and indicates their amorphous nature. Further heating of PVS-Ti(b)-300 sample caused generation of few broad hazy peaks (cf. Fig. 5) at Bragg angles $25.2^{\circ}, 37.8,48^{\circ}, 53.9^{\circ}, 55.1^{\circ}$, and $62.7^{\circ}$, which corresponds to the (101), (004), (200), (105), (211), and (204) planes of anatase- $\mathrm{TiO}_{2}$, respectively (JCPDS file no. 21-1272). The formation of anatase nanocrystals is due to the structural modification of Si-O-Ti bonds into Si-O and Ti$\mathrm{O}$ resulting in the nucleation and phase separation of $\mathrm{TiO}_{2}$ crystallites in the SiTiCNO matrix. Further, a fraction of these anatase- $\mathrm{TiO}_{2}$ transformed into rutile $\mathrm{TiO}_{2}$ (JCPDS file No. 77-0441) at $1300{ }^{\circ} \mathrm{C}$, which is confirmed by the presence of diffraction peaks at $27.4^{\circ}, 36^{\circ}, 41.1^{\circ}, 54.2^{\circ}, 56.5^{\circ}, 62.6^{\circ}$, and $68.8^{\circ}$ corresponding to diffraction plane of (110), (101), (111), (211), (220), and (221), respectively (Fig. 5). Interestingly, the formation of a new phase $\mathrm{TiC}_{0.3} \mathrm{~N}_{0.7}$ (JCPDS file no. 42-1488) was observed in addition to that of $\mathrm{TiO}_{2}$ within the ceramic for samples pyrolyzed at $1400^{\circ} \mathrm{C}$. This phase is generally formed due to the reaction of $\mathrm{TiO}_{2}$ with amorphous $\mathrm{SiCN}$ ceramics (Eq. 1).[42]

$$
\mathrm{zTiO}_{2}+\mathrm{SiC}_{\mathrm{x}} \mathrm{N}_{4-\mathrm{x}} \quad \rightarrow \quad z \mathrm{TiC}_{0.3} \mathrm{~N}_{0.7}+\mathrm{SiC}_{\mathrm{x}-1.3 \mathrm{z}} \mathrm{N}_{4-\mathrm{x}-0.7 \mathrm{z}}+\mathrm{zCO}_{2}
$$

The diffraction peaks of $\mathrm{TiC}_{0.3} \mathrm{~N}_{0.7}$ phase (at $36.5^{\circ}, 42.3^{\circ}$ and $61.4^{\circ}$ degree corresponding to (111), (200), (220) planes, respectively) indicate a substantial presence of the phase for the PVS-Ti(b)-1400 sample. Additionally for the $1400^{\circ} \mathrm{C}$ pyrolyzed samples, the formation of TiC (JCPDS file no. 73-0472) was observed, which could be confirmed from the diffraction peaks at $35.9^{\circ}, 41.7^{\circ}$ and $60.4^{\circ}$ corresponding to (111), (200), (220) planes, respectively. The TiC phase could be formed due to the reaction of $\mathrm{TiO}_{2}$ and $\mathrm{C}_{\text {free }}$ phases (Eq. 2).[43]

$\mathrm{TiO}_{2}+3 \mathrm{C} \rightarrow \mathrm{TiC}+2 \mathrm{CO}$ 
Thus, the PVS-Ti(b)-1400 sample was essentially found to be consisting of multiple phases including, rutile- $\mathrm{TiO}_{2}, \mathrm{TiC}, \mathrm{TiC}_{0.3} \mathrm{~N}_{0} \cdot 7$, and the nanodomains of $\mathrm{SiO}_{2}$ in the ceramic.

The XRD-patterns were fitted using Gaussian function after background subtraction and peak widths (full width at half maximum, FWHM) were calculated. The crystallite size of different evolved phases in different samples was calculated by Debye-Scherrer equation (cf. Table 1). Size of the anatase $\mathrm{TiO}_{2}$ was found to be $6.1 \mathrm{~nm}$ for the PVS-Ti(b)-1200 sample, which eventually grew to $9.9 \mathrm{~nm}$ and $10.4 \mathrm{~nm}$ for the PVS-Ti(b)-1300 and PVS-Ti(b)-1400 samples, respectively. Rutile and $\mathrm{TiC}_{0.3} \mathrm{~N}_{0.7}$ precipitates of $2.2 \mathrm{~nm}$ and $2.7 \mathrm{~nm}$ in the PVS-Ti(b)-1300 and coarsened to $13.6 \mathrm{~nm}$ and $3.2 \mathrm{~nm}$, respectively, for samples pyrolyzed at $1400{ }^{\circ} \mathrm{C}$. The TiC nanocrystals were of $4.6 \mathrm{~nm}$ in the SiTiCNO ceramics synthesized at 1400 ${ }^{\circ} \mathrm{C}$.

The $\mathrm{C}_{\text {free }}$ phase within the PDC influences their high temperature properties such as crystallization and oxidation resistance.[16,44,45] Thus it is important to understand the evolution of $\mathrm{C}_{\text {free }}$ in the prepared SiTiCNO ceramics. Fig. 6 shows Raman spectra of the SiTiCNO ceramics prepared at different temperatures, which clearly exhibits the presence of $D$ and $G$ bands of graphitic carbon. The $D$ band appears due to the out of plane vibration caused by laser scattering from local defects present in $\mathrm{C}_{\text {free, }}$ whereas the $\mathrm{G}$ band is a result of in-plane vibrations of $\mathrm{sp}^{2}$ bonded carbon atoms caused by tangential stretching of the $\mathrm{sp}^{2}$ bonded carbon in the graphitic structure.[46, 47] The Raman spectra of few undoped samples (synthesized in the similar conditions) were also presented in Fig. 6 for comparison purpose. The $D, G$ peak positions, their width, and the size of $C_{\text {free }}$ were calculated (listed in Table 2) after the base line correction of spectra followed by the peak fittings using Lorentzian function.

Table 1: Size analysis of different evolved phases within the SiTiCNO ceramics.

\begin{tabular}{|lllll|}
\hline Sample Name & $2 \rrbracket$ & FWHM & Crystallite Size(nm) & Phases \\
\hline PVS-Ti(b)-1200 & 25.2 & 1.4 & 6.1 & Anatase-TiO 2 \\
& 25.2 & 0.86 & 9.9 & Anatase-TiO 2 \\
PVS-Ti(b)-1300 & 27.4 & 3.85 & 2.2 & Rutile-TiO $_{2}$ \\
& 42.3 & 3.3 & 2.7 & TiC $_{0.3} \mathrm{~N}_{0.7}$ \\
\hline PVS-Ti(b)-1400 & 25.2 & 0.82 & 10.4 & Anatase-TiO \\
& 27.4 & 0.63 & 13.6 & Rutile-TiO \\
& 41.7 & 1.92 & 4.6 & TiC $_{2}$ \\
\hline & 42.3 & 2.80 & 3.2 & TiC $_{0.3} \mathrm{~N}_{0.7}$ \\
\hline
\end{tabular}


The $D$ and $G$ peaks were observed in the SiTiCNO samples over the spectral range of $1326-1340 \mathrm{~cm}^{-1}$ and 1589-1614 $\mathrm{cm}^{-1}$, respectively (Table 2). In the Raman spectra of pure SiCN samples (PVS-1000 and PVS-1400), the $D$ and $G$ peaks appeared at $\sim 1330$ and $\sim 1620 \mathrm{~cm}^{-1}$. Presence of these $D$ and $G$ Raman bands for all the pyrolyzed PVS-Ti(b) samples suggests that the formation of the $\mathrm{C}_{\text {free }}$ phases started at earlier temperature (even at $900^{\circ} \mathrm{C}$ ) in the Ti doped SiCN ceramics than the undoped SiCN ceramics. It could be concluded that $\mathrm{Ti}$ doping in the SiCN matrix accelerates formation of the free carbon phase $\left(\mathrm{C}_{\text {free }}\right)$.

Initially blue shift of the $\mathrm{G}$ bands was observed for the SiTiCNO samples pyrolyzed up to $1200^{\circ} \mathrm{C}$. The lack of meaningful signal intensity of the G peak in the PVS-1000 sample is attributable to fluorescence, which indicates substantial polymeric existence and considerable amount of hydrogen still being present in the pyrolyzed ceramic. Therefore, it could be concluded that amorphous carbon nanostructures dominate in the samples pyrolyzed up to $1200^{\circ} \mathrm{C}$. The ratio of integral intensity of $\mathrm{D}$ and $\mathrm{G}$ peaks increases for high temperature pyrolysis (cf. Table 2). The $\mathrm{G}$ peak from $1614 \mathrm{~cm}^{-1}$ of the PVS-Ti(b)-1200 sample clearly redshifts to $1590 \mathrm{~cm}^{-1}$ in the PVS-Ti(b)-1300 and PVS-Ti(b)-1400 samples (cf. Table 2) indicating graphitization of the $\mathrm{C}_{\text {free }} \cdot[48]$ However, in the Raman spectrum of the undoped PVS-1400 sample, there were no major shifts observed in the $D$ and $G$ peak position. Nevertheless, the $D$ and $G$ peaks were sharper for the PVS-1400 samples than those of PVS-1000, which could be attributed to the graphitization of the $\mathrm{C}_{\text {free }}$ present in SiCN ceramics at $1400^{\circ} \mathrm{C}$.

Table 2: Calculation of Full width at half of maximum (FWHM) of D \& $G$ band and carbon nanodomains present in different SiTiCNO samples after pyrolysis.

\begin{tabular}{|lllllll|}
\hline Sample Name & $D$ & $G$ & FWHM(D) & FWHM(G) & $\left(I_{D} / I_{G}\right)$ & La (in nm) \\
\hline PVS-1000 & 1328 & 1621 & 199.98 & 359.92 & 1.59 & 3.1 \\
\hline PVS-Ti(b)-1000 & 1335 & 1601 & 125.44 & 64.91 & 1.30 & 3.8 \\
\hline PVS-Ti(b)-1100 & 1340 & 1606 & 157.71 & 67.83 & 1.63 & 3.1 \\
\hline PVS-Ti(b)-1200 & 1326 & 1614 & 127.54 & 62.97 & 2.04 & 2.4 \\
\hline PVS-Ti(b)-1300 & 1329 & 1590 & 139.10 & 57.24 & 1.95 & 2.5 \\
\hline PVS-Ti(b)-1400 & 1338 & 1590 & 130.27 & 55.52 & 1.90 & 2.6 \\
\hline PVS-1400 & 1330 & 1616 & 114.50 & 89.67 & 1.99 & 2.5 \\
\hline
\end{tabular}

The FWHM of G peak for the PVS-1400 spectrum are larger than the corresponding values of $\mathrm{G}$ peak widths for all the pyrolyzed Ti doped PVS samples (cf. Table 2). Similar observations can be made for the $\frac{I_{D}}{I_{G}}$ values (except for the PVS-Ti(b)-1200 sample, which was comparable) Therefore, it can be surmised that Ti doping in the SiCN matrix promotes ordering of the $\mathrm{C}_{\text {free }}$ phase. There were no major changes in 
the $\mathrm{D}$ peak widths of the doped and undoped samples. Further, residual $\mathrm{C}_{\text {free }}$ knot size $\left(L_{a}\right)$ in the SiTiCNO ceramics were calculated (cf. Table 2 for values) by using Tuinstra-Koenig relation (Eq. 3) [49]-

$$
L_{a}=\frac{C(\lambda)}{\frac{I_{D}}{I_{G}}}
$$

3

For the laser beam used in this study (laser wavelength, $\lambda=532 \mathrm{~nm}$ ), $C$ is $\sim 4.95 \mathrm{~nm}$. [50, 51] No major change in the dimensions of the nanocrystals of residual carbon between the undoped and doped samples when the pyrolysis temperature was $1200^{\circ} \mathrm{C}$ or higher. The sample PVS-1000 and PVS$\mathrm{Ti}(\mathrm{b})-1000$ showed a larger $L_{a}$ than the high temperature pyrolyzed samples. The main reason behind it is the pyrolysis temperature $\left(1000^{\circ} \mathrm{C}-1100^{\circ} \mathrm{C}\right)$, which is apparently very low to eradicate remaining hydrogen attached with the carbon.[52] It is interesting to note that though the carbon segregates at earlier temperatures into SiTiCNO matrices but the lateral size of carbon nanocrystals remain fine even at $1400{ }^{\circ} \mathrm{C}$ ( $2.6 \mathrm{~nm}$ size range). Therefore, it can be concluded that Ti doping to SiCN does not affect crystallite size of the $\mathrm{C}_{\text {free }}$ phase.

The different nanostructures developed within the SiTiCNO ceramics during pyrolysis at $1400{ }^{\circ} \mathrm{C}$ as evidenced by XRD analysis, were observed through TEM/HRTEM, as presented in Fig. 7 and Fig. 8. Micrographs shown in Fig. 7a, Fig. 7b and Fig. 7c display a homogeneous distribution of the nanocrystals evolved within the SiCN matrix at different microscope resolution. In Fig. 7d, mixed precipitates of small (grayish dot structures) and relatively larger nanocrystals appear. The nanocrystals could be observed in spherical, elliptical, as well as cuboid shape, with sizes ranging from a few to $12 \mathrm{~nm}$. These nanostructures were further identified by analyzing it through HRTEM as shown in Fig. 8.

Fig. 8a and Fig. 8b show different lattice fringes of the nanostructures evolved within the ceramic matrix. Also, the SiCN matrix clearly appeared amorphous in nature. The insets within the HRTEM images shows IFFT image of the selected areas for the calculation of the respective lattice fringe widths. The lattice fringe width computed as $0.32 \mathrm{~nm}$ corresponds to the d-spacing of (110) plane of rutile-TiO 2 (JCPDS file No. 77-0441). The fringe widths corresponding to $0.35 \mathrm{~nm}$, and $0.24 \mathrm{~nm}$, belong to the d-spacing of (101) and (004) planes of anatase-TiO 2 (JCPDS \#21-1272), respectively. Also, the fringe width measured as $0.25 \mathrm{~nm}$ corresponds to the d-spacing of (111) plane of TiC (JCPDS file no. 73-0472). These observations of the different phases in an amorphous SiCN matrix are in confirmation with the X-ray diffractograms (Fig. 6). Other than these, an unusual lattice fringe of $0.445 \mathrm{~nm}$ width was reported, which belongs to (200) plane of the silicon oxynitride $\left(\mathrm{Si}_{2} \mathrm{~N}_{2} \mathrm{O}\right)$ phase (JCPDS file No. 84-1814). Although $\mathrm{Si}_{2} \mathrm{~N}_{2} \mathrm{O}$ phase did not appear in the XRD pattern, in the given circumstances the only plausible phase belonging to the lattice width of $0.445 \mathrm{~nm}$ could be of $\mathrm{Si}_{2} \mathrm{~N}_{2} \mathrm{O}$. The formation mechanism and sequence of the $\mathrm{Si}_{2} \mathrm{~N}_{2} \mathrm{O}$ phase in the SiTiCNO system is not clear at the moment. However, $\mathrm{Si}_{2} \mathrm{~N}_{2} \mathrm{O}$ phase had been developed earlier in a similar system by Cheng et al. through polysilyloxycarbodiimide precursors derived SiCN 
system.[53] The $\mathrm{TiC}_{0.3} \mathrm{~N}_{0.7}$ nanocrystals are not identified through the HRTEM images, probably due to the low amount and random distribution. However, the grayish dot like nanostructures (Fig. 7d) could be referred to the $\mathrm{TiC}_{0.3} \mathrm{~N}_{0.7}$ phases, since their crystallite size calculated through diffraction curve ( 3.2 nm) belongs in the size range of the crystals observed in the TEM micrograph. The average crystallite size of rutile- $\mathrm{TiO}_{2}$, anatase- $\mathrm{TiO}_{2}$, and $\mathrm{TiC}$ measured in $\mathrm{HRTEM}$ micrographs were $11.5 \mathrm{~nm}, 10.7 \mathrm{~nm}$, and $5.2 \mathrm{~nm}$, respectively, which are in good agreement with the crystallite sizes obtained by the Scherrer equation (cf. Table 1). TEM micrographs clearly show that these interphase nanoparticles are fully separated by SiCN glass boundaries and are well distributed within the amorphous ceramic matrix.

In many previous studies, efforts have been made to develop Ti doped SiCN/SiOC ceramics with a stable nanostructure at high temperatures. The dopant precursor sources influence the evolution of nanostructures within the PDC during pyrolysis, which consequently influence materials properties. For instance, TiN nanocrystals within SiOCN matrix were observed from the thermolysis of titanium tetrabutoxide modified polyhydridomethylsiloxane at $1000^{\circ} \mathrm{C}$ in ammonia, and subsequent annealing at $1200^{\circ} \mathrm{C}$ in nitrogen.[54] In another work, titanium isopropoxide modified polymethylphenylsilsesquioxane precursor formed $\mathrm{TiC}-\mathrm{SiOC}$ ceramics at $1000^{\circ} \mathrm{C}$.[55] The $\mathrm{TiC}$ within the SiOC significantly improved the oxidation resistance of the SiTiOC nanocomposite. Ti doping using titanium isopropoxide to polyvinylsilazane resulted in the precipitation of anatase- $-\mathrm{TiO}_{2}$ within the $\mathrm{SiCN}$ ceramics at $1100{ }^{\circ} \mathrm{C}$ and a small fraction of the anatase- $\mathrm{TiO}_{2}$ phase converted into rutile- $\mathrm{TiO}_{2}$ at $1200^{\circ} \mathrm{C}$.[37] Such nanocrystallites of anatase- $\mathrm{TiO}_{2}$ within the $\mathrm{SiCN}$ ceramic matrix improved ceramic yield (during pyrolysis) as well as oxidation resistance of the ceramics up to $1400{ }^{\circ} \mathrm{C}$. Further, the pyrolysis of titanium tetrabutoxide altered polyhydridomethylsiloxane precursor led to the formation of nanocrystallites of anatase- $\mathrm{TiO}_{2}$ in $\mathrm{SiOC}$ matrix that remained stable up to $1200^{\circ} \mathrm{C}$.[56] Similarly, in the current investigation the rutile- $\mathrm{TiO}_{2}$ was found predominantly at $1300^{\circ} \mathrm{C}$ and $1400^{\circ} \mathrm{C}$ in the amorphous SiCN matrix. TiC is a high temperature ceramic (melting point of $3067^{\circ} \mathrm{C}$ ) that shows excellent resistance towards high temperature creep, corrosion, and thermal shock. [57] Further, TiC shows high hardness (28-35 GPa), high elastic modulus (450 GPa) and good thermal conductivity $(22-35 \mathrm{~W} /(\mathrm{m} \cdot \mathrm{K})$ ). [58] Formation of TiC in the SiTiCNO composite in the current investigation imparts beneficial high temperature properties. The formation of $\mathrm{TiC}_{0.3} \mathrm{~N}_{0.7}$ is very rare and it has got properties similar to that of $\mathrm{TiC}$ and $\mathrm{TiN}$.[58] Moreover, $\mathrm{Si}_{2} \mathrm{~N}_{2} \mathrm{O}$ has low diffusion coefficient and shows excellent properties, such as excellent oxidation resistance (up to $1600^{\circ} \mathrm{C}$ ), high thermodynamic stability (up to $1800^{\circ} \mathrm{C}$ and more stable than $\mathrm{Si}_{3} \mathrm{~N}_{4}$ ), high flexural strength (up to $1400^{\circ} \mathrm{C}$ ), high thermal shock resistance, and high fracture toughness. $[59,60]$ The carbon in the PDC matrix acts as barrier and improves their thermal stability towards crystallization and decomposition.[16] Therefore, assimilation of all the results and the formed phases indicates the formation of a multicomponent multiphase nanocomposites ceramics with the simple doping of $\mathrm{Ti}$ in a polysilazane based preceramic polymer. The formation of such a composite with nanostructured phases of $\mathrm{TiO}_{2}, \mathrm{C}, \mathrm{TiC}, \mathrm{TiC}_{0.3} \mathrm{~N}_{0.7}$, and $\mathrm{Si}_{2} \mathrm{~N}_{2} \mathrm{O}$ dispersed in an amorphous $\mathrm{SiCN}$ matrix, which is stable at $1400{ }^{\circ} \mathrm{C}$, promises structural stability and better high temperature properties. These compounds merit exploration 
as functional materials, high temperature coatings, and engineered intergranular phase compounds in bulk ceramic components.

\section{Summary}

The present investigation describes synthesis, high-temperature stability, and microstructure evolution of SiTiCNO ceramics. Polyvinylsilazane precursor was mixed with tetrabutyl orthotitanate and subsequently crosslinked at $300^{\circ} \mathrm{C}$ and pyrolyzed in the range of $900{ }^{\circ} \mathrm{C}-1400{ }^{\circ} \mathrm{C}$ in flowing nitrogen atmosphere to get SiTiCNO ceramics. The precursor to ceramic conversion completed at $750^{\circ} \mathrm{C}$ and the Ti incorporated SiCN ceramics remained as a single phase SiTiCNO ceramic up to $1100^{\circ} \mathrm{C}$. SEM-EDX confirmed uniform doping of $\mathrm{Ti}$ in the SiCN ceramic matrix. Ti-doping in SiCN ceramics was found to promote the phase separation of the carbon phase. The free carbon phase was found to possess netter graphitic structural order in the Ti-doped SiCN as compared to the undoped ceramic for equivalent thermal history. However, doping did not affect the lateral size of the free carbon phase. The Ti-doped SiCN ceramics annealed at $1200{ }^{\circ} \mathrm{C}$ exhibited formation of nanocrystallites of anatase- $\mathrm{TiO}_{2}$ (size $\sim 6.1 \mathrm{~nm}$ ) thus forming a $\mathrm{TiO}_{2}{ }^{-}$ SiCN-C nanocomposite. At $1300{ }^{\circ} \mathrm{C}$, these anatase- $\mathrm{TiO}_{2}$ converted into rutile- $\mathrm{TiO}_{2}$ and the carbothermal decomposition of SiCN matrix produced high temperature stable $\mathrm{TiC}_{0.3} \mathrm{~N}_{0.7}$ phase. Further annealing of the SiTiCNO materials at $1400^{\circ} \mathrm{C}$, produced novel multiphase and multicomponent ceramic nanocomposite system consisting of phases, such as $\mathrm{TiO}_{2}, \mathrm{SiCN}, \mathrm{C}, \mathrm{TiC}, \mathrm{TiC}_{0.3} \mathrm{~N}_{0.7}$, and $\mathrm{Si}_{2} \mathrm{~N}_{2} \mathrm{O}$. These constituent phases were of few nanometers to $13.6 \mathrm{~nm}$ in size and distributed throughout glassy SiCN matrix. The results presented in this work indicate the formation of a unique multiphase nanostructured composite with excellent thermal stability that merit further exploration of potential for high temperature structural and functional applications.

\section{References}

1. M. Friess, J. Bill, J. Golczewski, A. Zimmermann, F. Aldinger, R. Riedel, R. Raj, Crystallization of Polymer-Derived Silicon Carbonitride at $1873 \mathrm{~K}$ under Nitrogen Overpressure, J. Am. Ceram. Soc., 85 (2002) 2587-2589.

2. E. Bernardo, I. Ponsot, P. Colombo, S. Grasso, H. Porwal, M.J. Reece, Polymer-derived SiC ceramics from polycarbosilane/boron mixtures densified by SPS, Ceram. Int., 40 (2014) 14493-14500.

3. B. Baufeld, H. Gu, J. Bill, F. Wakai, F. Aldinger, High Temperature Deformation of Precursor-derived Amorphous Si-B-C-N Ceramics, J. Eur. Ceram. Soc., 19 (1999) 2797-2814.

4. K. Terauds, D.B. Marshall, R. Raj, Oxidation of Polymer-Derived HfSiCNO up to $1600^{\circ} \mathrm{C}$, J. Am. Ceram. Soc., 96 (2013) 1278-1284.

5. S. Jothi, S. Ravindran, L. Neelakantan, R. Kumar, Corrosion behavior of polymer-derived SiHfCN(O) ceramics in salt and acid environments, Ceram. Int., 41 (2015) 10659-10669.

6. M. Günthner, A. Schütz, U. Glatzel, K. Wang, R.K. Bordia, O. GreißI, W. Krenkel, G. Motz, High performance environmental barrier coatings, Part I: Passive filler loaded SiCN system for steel, J. Eur. 
Ceram. Soc., 31 (2011) 3003-3010.

7. R. Anand, A. Mohanty, S.K. Behera, Kinetics of Mullitization from Polysilsesquioxane and Boehmite Precursors, Trans. Indian Ceram. Soc., 80 (2021) 55-59.

8. K. Tangermann-Gerk, G. Barroso, B. Weisenseel, P. Greil, T. Fey, M. Schmidt, G. Motz, Laser pyrolysis of an organosilazane-based glass/Z $\mathrm{rO}_{2}$ composite coating system, Mater. Des., 109 (2016) 644-651.

9. L. Neckel Jr, A.G. Weiss, G. Motz, D. Hotza, M.C. Fredel, Particle-Filled Polysilazane Coatings for Steel Protection, Advanced Materials Research, 975 (2014) 149-153.

10. D. Hotza, R.K. Nishihora, R.A.F. Machado, P.-M. Geffroy, T. Chartier, S. Bernard, Tape casting of preceramic polymers toward advanced ceramics: A review, International Journal of Ceramic Engineering \& Science, 1 (2019) 21-41.

11. T. Kraus, M. Günthner, W. Krenkel, G. Motz, cBN particle filled SiCN precursor coatings, Advances in Applied Ceramics, 108 (2009) 476-482.

12. N. Martins, T. Bendo, M. Seifert, A. Medeiros, P.C. Gonçalves, T.D. Justus, J. Cardoso de Lima, G. Motz, A.N. Klein, Plasma assisted pyrolysis for processing of composite ceramic coatings based on silazane precursor and $\mathrm{TiB}_{2}$ filler applied onto a sintered steel, Open Ceramics, 4 (2020) 100036.

13. L.V. Interrante, W.R. Schmidt, P.S. Marchetti, G.E. Maciel, Preparation of Non-Oxide Ceramics by Pyrolysis of Organometallic Precursors, MRS Proceedings, 271 (2011) 739.

14. A. Viard, D. Fonblanc, D. Lopez-Ferber, M. Schmidt, A. Lale, C. Durif, M. Balestrat, F. Rossignol, M. Weinmann, R. Riedel, S. Bernard, Polymer Derived Si-B-C-N Ceramics: 30 Years of Research, Adv. Eng. Mater., 20 (2018) 1800360.

15. P. Colombo, G. Mera, R. Riedel, G.D. Sorarù, Polymer-Derived Ceramics: 40 Years of Research and Innovation in Advanced Ceramics, J. Am. Ceram. Soc., 93 (2010) 1805-1837.

16. Q. Wen, Z. Yu, R. Riedel, The fate and role of in situ formed carbon in polymer-derived ceramics, Progress in Materials Science, 109 (2020) 100623.

17. L. An, R. Riedel, C. Konetschny, H.J. Kleebe, R. Raj, Newtonian Viscosity of Amorphous Silicon Carbonitride at High Temperature, J. Am. Ceram. Soc., 81 (1998) 1349-1352.

18. O. Flores, R.K. Bordia, D. Nestler, W. Krenkel, G. Motz, Ceramic Fibers Based on SiC and SiCN Systems: Current Research, Development, and Commercial Status, Adv. Eng. Mater., 16 (2014) 621-636.

19. B. Papendorf, K. Nonnenmacher, E. Ionescu, H.J. Kleebe, R. Riedel, Strong influence of polymer architecture on the microstructural evolution of hafnium-alkoxide-modified silazanes upon ceramization, Small (Weinheim an der Bergstrasse, Germany), 7 (2011) 970-978.

20. R. Anand, S.P. Sahoo, B.B. Nayak, S.K. Behera, Phase evolution in Zr-doped preceramic polymer derived SiZrOC hybrids, Ceram. Int., 46 (2020) 9962-9967.

21. L. An, Y. Wang, L. Bharadwaj, L. Zhang, Y. Fan, D. Jiang, Y. Sohn, V.H. Desai, J. Kapat, L.C. Chow, Silicoaluminum Carbonitride with Anomalously High Resistance to Oxidation and Hot Corrosion, Advanced Engineering Materials, 6 (2004) 337-340. 
22. Y. Wang, W. Fei, L. An, Oxidation/Corrosion of Polymer-Derived SiAICN Ceramics in Water Vapor, Journal of the American Ceramic Society, 89 (2006) 1079-1082.

23. Y. Iwamoto, K.-i. Kikuta, S.-i. Hirano, $\mathrm{Si}_{3} \mathrm{~N}_{4}-\mathrm{TiN}-\mathrm{Y}_{2} \mathrm{O}_{3}$ ceramics derived from chemically modified perhydropolysilazane, J. Mater. Res., 14 (2011) 4294-4301.

24. Y. Iwamoto, K.-i. Kikuta, S.-i. Hirano, Synthesis of Poly-Titanosilazanes and Conversion into $\mathrm{Si}_{3} \mathrm{~N}_{4}-\mathrm{TiN}$ Ceramics, J. Ceram. Soc. JAPAN, 108 (2000) 350-356.

25. G. Motz, J. Hacker, G. Ziegler, Special Modified Silazanes for Coatings, Fibers and CMC'S, 24th Annual Conference on Composites, Advanced Ceramics, Materials, and Structures: B: Ceramic Engineering and Science Proceedings 2000, pp. 307-314.

26. A. Saha, S.R. Shah, R. Raj, Amorphous Silicon Carbonitride Fibers Drawn from Alkoxide Modified Ceraset $^{\text {TM }}$, Journal of the American Ceramic Society, 86 (2003) 1443-1445.

27. A. Saha, S.R. Shah, R. Raj, Oxidation Behavior of $\mathrm{SiCN}-\mathrm{ZrO}_{2}$ Fiber Prepared from Alkoxide-Modified Silazane, J. Am. Ceram. Soc., 87 (2004) 1556-1558.

28. R. Anand, B.B. Nayak, S.K. Behera, Coarsening kinetics of nanostructured $\mathrm{ZrO}_{2}$ in $\mathrm{Zr}$-doped $\mathrm{SiCN}$ ceramic hybrids, J. Alloys Compd., 811 (2019) 151939.

29. K. Terauds, R. Raj, Limits to the Stability of the Amorphous Nature of Polymer-Derived HfSiCNO Compounds, Journal of the American Ceramic Society, 96 (2013) 2117-2123.

30. G. Mera, M. Gallei, S. Bernard, E. Ionescu, Ceramic Nanocomposites from Tailor-Made Preceramic Polymers, Nanomaterials, 5 (2015) 468.

31. Q. Wen, Z. Yu, Y. Xu, Y. Lu, C. Fasel, K. Morita, O. Guillon, G. Buntkowsky, E. Ionescu, R. Riedel, $\mathrm{SiC} / \mathrm{Hf}_{\mathrm{y}} \mathrm{Ta}_{1-\mathrm{y}} \mathrm{C}_{\mathrm{x}} \mathrm{N}_{1-\mathrm{x}} / \mathrm{C}$ ceramic nanocomposites with $\mathrm{Hf}_{\mathrm{y}} \mathrm{Ta}_{1-\mathrm{y}} \mathrm{C}_{\mathrm{x}} \mathrm{N}_{1-\mathrm{x}}$-carbon core-shell nanostructure and the influence of the carbon-shell thickness on electrical properties, Journal of Materials Chemistry C, 6 (2018) 855-864.

32. Q. Wen, Y. Feng, Z. Yu, D.-L. Peng, N. Nicoloso, E. Ionescu, R. Riedel, Microwave Absorption of $\mathrm{SiC} / \mathrm{HfC}_{x} \mathrm{~N}_{1-x} / \mathrm{C}$ Ceramic Nanocomposites with $\mathrm{HfC}_{x} \mathrm{~N}_{1-x}$-Carbon Core-Shell Particles, J. Am. Ceram. Soc., 99 (2016) 2655-2663.

33. R. Anand, B.B. Nayak, S.K. Behera, Effect of zirconium on precursor chemistry, phase stability, and oxidation of polyvinylsilazane-derived SiCN ceramics, J. Mater. Sci., (2022).

34. Z.-C. Wang, F. Aldinger, R. Riedel, Novel Silicon-Boron-Carbon-Nitrogen Materials Thermally Stable up to $2200^{\circ} \mathrm{C}, \mathrm{J}$. Am. Ceram. Soc., 84 (2001) 2179-2183.

35. B. Feng, J. Peter, C. Fasel, Q. Wen, Y. Zhang, H.-J. Kleebe, E. lonescu, High-temperature phase and microstructure evolution of polymer-derived SiZrCN and SiZrBCN ceramic nanocomposites, J. Am. Ceram. Soc., 103 (2020) 7001-7013.

36. R. Anand, B.B. Nayak, S.K. Behera, Thermostructural evolution of Hf-doped silazane derived SiCN ceramic hybrids, Manuscript under preparation, (2021).

37. R. Anand, B.B. Nayak, S.K. Behera, Phase, nanostructure, and oxidation of precursor derived SiCN$\mathrm{TiO}_{2}$ ceramic nanocomposites, Ceram. Int., 47 (2021) 27822-27832. 
38. M. Seifert, N. Travitzky, W. Krenkel, G. Motz, Multiphase ceramic composites derived by reaction of $\mathrm{Nb}$ and SiCN precursor, Journal of the European Ceramic Society, 34 (2014) 1913-1921.

39. X. Wang, F. Schmidt, D. Hanaor, P.H. Kamm, S. Li, A. Gurlo, Additive manufacturing of ceramics from preceramic polymers: A versatile stereolithographic approach assisted by thiol-ene click chemistry, Addit. Manuf., 27 (2019) 80-90.

40. M. Januś, K. Kyzioł, S. Kluska, J. Konefat-Góral, A. Małek, S. Jonas, Plasma Assisted Chemical Vapour Deposition - Technological Design Of Functional Coatings, Arch. Metall. Mater., 60 (2015) 909-914.

41. K. Terauds, R. Raj, P. Kroll, Ab inito and FTIR Studies of HfSiCNO Processed from the Polymer Route, J. Am. Ceram. Soc., 97 (2014) 742-749.

42. R.-G. Duan, J.D. Kuntz, J.E. Garay, A.K. Mukherjee, Metal-like electrical conductivity in ceramic nanocomposite, Scr. Mater., 50 (2004) 1309-1313.

43. G.A. Swift, R. Koc, Formation studies of TiC from carbon coated $\mathrm{TiO}_{2}$, J. Mater. Sci., 34 (1999) 30833093.

44. S. Trassl, H.-J. Kleebe, H. Störmer, G. Motz, E. Rössler, G. Ziegler, Characterization of the Free-Carbon Phase in Si-C-N Ceramics: Part II, Comparison of Different Polysilazane Precursors, J. Am. Ceram. Soc., 85 (2002) 1268-1274.

45. L. Ribeiro, A. Bezerra, C. Gervais, S. Bernard, R. Machado, G. Motz, The influence of pyrolysis temperature on the oxidation resistance of carbon-rich SiCN ceramics derived from reaction of silazanes with acrylonitrile, J. Eur. Ceram. Soc., (2021).

46. Y. Wang, D.C. Alsmeyer, R.L. McCreery, Raman spectroscopy of carbon materials: structural basis of observed spectra, Chemistry of Materials, 2 (1990) 557-563.

47. A.C. Ferrari, J. Robertson, Interpretation of Raman spectra of disordered and amorphous carbon, Phys. Rev. B, 61 (2000) 14095-14107.

48. F. Roth, P. Waleska, C. Hess, E. lonescu, N. Nicoloso, UV Raman spectroscopy of segregated carbon in silicon oxycarbides, J. Ceram. Soc. JAPAN, 124 (2016) 1042-1045.

49. L.G. Cançado, K. Takai, T. Enoki, M. Endo, Y.A. Kim, H. Mizusaki, A. Jorio, L.N. Coelho, R. MagalhãesPaniago, M.A. Pimenta, General equation for the determination of the crystallite size La of nanographite by Raman spectroscopy, Applied Physics Letters, 88 (2006) 163106.

50. F. Tuinstra, J.L. Koenig, Raman Spectrum of Graphite, J. Chem. Phys., 53 (1970) 1126-1130.

51. T. Jiang, Y. Wang, Y. Wang, N. Orlovskaya, L. An, Quantitative Raman Analysis of Free Carbon in Polymer-Derived Ceramics, J. Am. Ceram. Soc., 92 (2009) 2455-2458.

52. J. Kaspar, M. Graczyk-Zajac, R. Riedel, Lithium insertion into carbon-rich SiOC ceramics: Influence of pyrolysis temperature on electrochemical properties, Journal of Power Sources, 244 (2013) 450-455.

53. H. Cheng, Y. Li, E. Kroke, S. Herkenhoff, In situ synthesis of $\mathrm{Si}_{2} \mathrm{~N}_{2} \mathrm{O} / \mathrm{Si}_{3} \mathrm{~N}_{4}$ composite ceramics using polysilyloxycarbodiimide precursors, J. Eur. Ceram. Soc., 33 (2013) 2181-2189. 
54. E.W. Awin, A. Lale, K.C.H. Kumar, U.B. Demirci, S. Bernard, R. Kumar, Plasmon enhanced visible light photocatalytic activity in polymer-derived TiN/Si-O-C-N nanocomposites, Mater. Des., 157 (2018) 8796.

55. R. Anand, S.P. Sahoo, B.B. Nayak, S.K. Behera, Phase evolution, nanostructure, and oxidation resistance of polymer derived SiTiOC ceramic hybrid, Ceram. Int., 45 (2019) 6570-6576.

56. E.W. Awin, A. Lale, K.C.N.H. Kumar, U.B. Demirci, S. Bernard, R. Kumar, Novel Precursor-Derived Meso-/Macroporous TiO\&/SiOC Nanocomposites with Highly Stable Anatase Nanophase Providing Visible Light Photocatalytic Activity and Superior Adsorption of Organic Dyes, Materials, 11 (2018).

57. W. Lengauer, Transition Metal Carbides, Nitrides, and Carbonitrides, Handbook of Ceramic Hard Materials 2000, pp. 202-252.

58. M. Szutkowska, S. Cygan, M. Podsiadło, J. Laszkiewicz-Łukasik, J. Cyboroń, A. Kalinka, Properties of $\mathrm{TiC}$ and TiN Reinforced Alumina-Zirconia Composites Sintered with Spark Plasma Technique, Metals, 9 (2019).

59. X. Li, L. Zhang, X. Yin, Study on in-situ reaction synthesis and mechanical properties of $\mathrm{Si}_{2} \mathrm{~N}_{2} \mathrm{O}$ ceramic, Ceram. Int., 39 (2013) 3035-3041.

60. M. Ohashi, S. Kanzaki, H. Tabata, Processing, Mechanical Properties, and Oxidation Behavior of Silicon Oxynitride Ceramics, J. Am. Ceram. Soc., 74 (1991) 109-114.

\section{Figures}

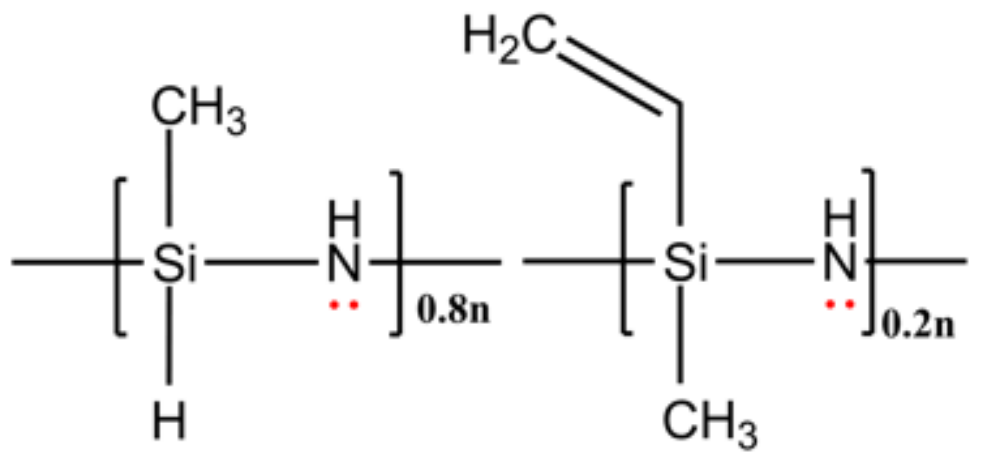

Figure 1

Molecular structure of Durazane ${ }^{\circledR} 1800$ precursor. 


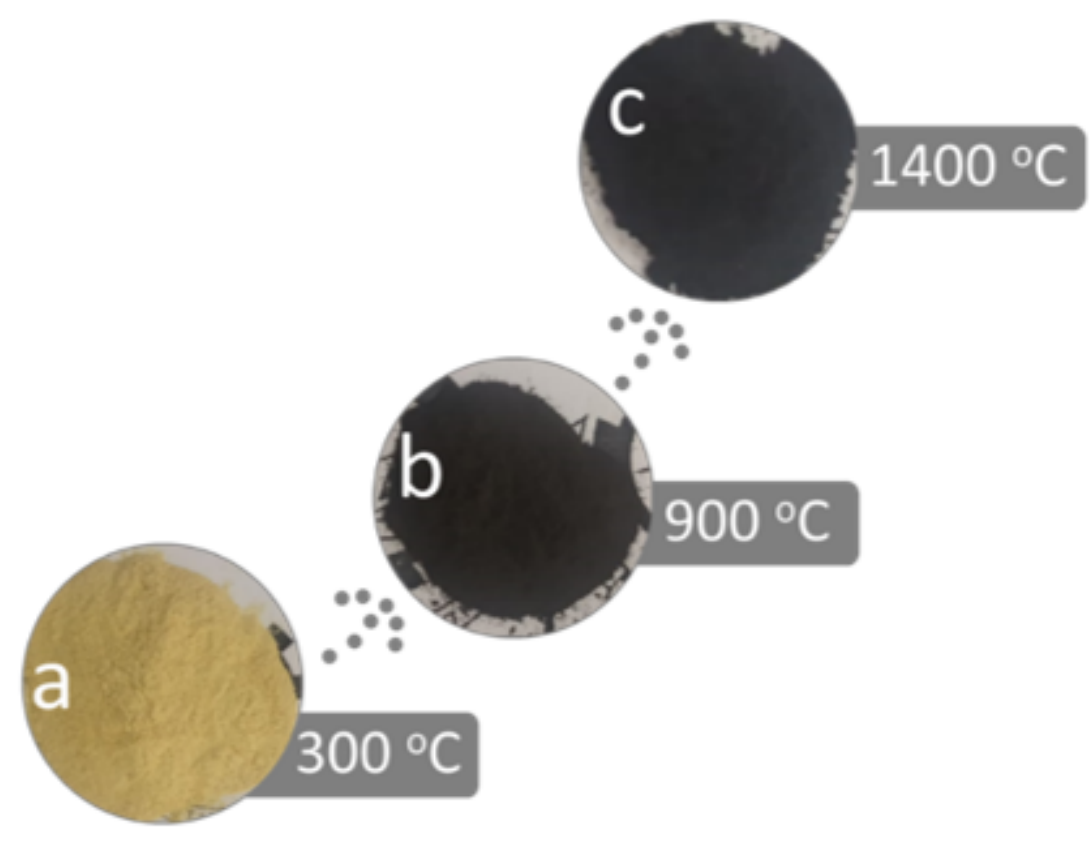

Figure 2

(a) High energy milled PVS-Ti(b)-300 powder (b) PVS-Ti(b)-900 powder (c) PVS-Ti(b)-1400 powder.

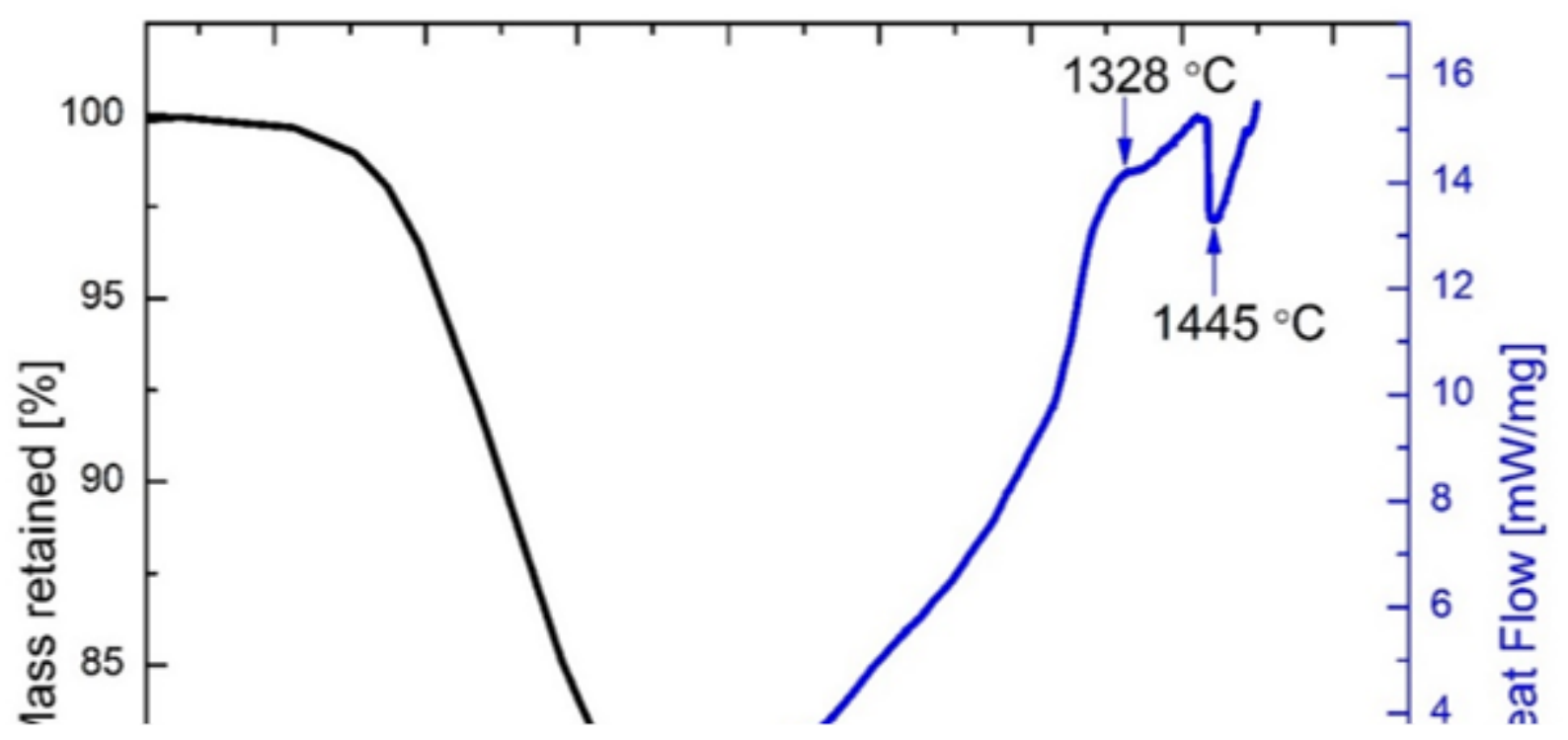


Figure 3

TGA-DSC curve of crosslinked PVS-Ti(b)-300 precursor in nitrogen atmosphere.

Figure 4

(a) Scanning electron micrograph of the PVS-Ti(b)-1400 sample, (b-f) EDS elemental distribution of Si, $\mathrm{Ti}$, $\mathrm{C}, \mathrm{N}$, and $\mathrm{O}$ in the ceramic matrix respectively.

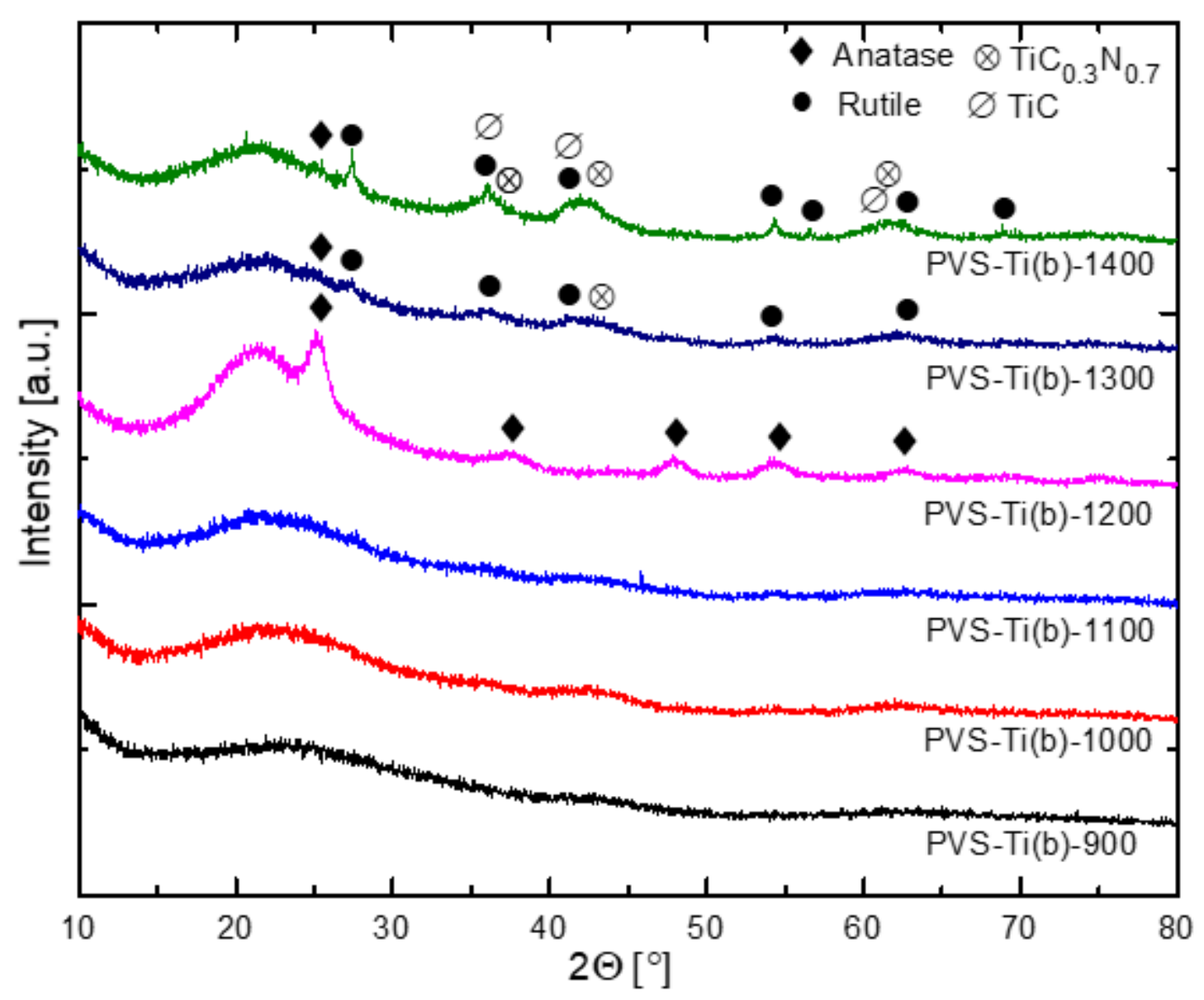

Figure 5

X-ray diffractograms of PVS-Ti(b) samples synthesized at $900^{\circ} \mathrm{C}$ to $1400^{\circ} \mathrm{C}$.

Figure 6 
Raman spectra of SiCN and SiTiCNO ceramics synthesized at $1000^{\circ} \mathrm{C}-1400^{\circ} \mathrm{C}$.

\section{Figure 7}

Transmission electron micrographs (bright filed) (a-d) of PVS-Ti(b)-1400 sample taken at different magnifications exhibiting fine distributions of nanostructured phases within the SiCN matrix.

\section{Figure 8}

High resolution transmission electron micrographs (phase contrast images) of PVS-Ti(b)-1400 samples exhibiting different lattice fringes corresponding to the different nanostructured phases dispersed throughout SiCN matrix, (insets show IFFT images of the corresponding areas). 